\title{
Internet Addiction and Happiness Among Medical Sciences Students in Southeastern Iran
}

\author{
Hossein Ansari, ${ }^{1, *}$ Alireza Ansari-Moghaddam, ${ }^{1}$ Mahdi Mohammadi, ${ }^{1}$ Mostafa Peyvand, \\ Zahra Amani, and Azizollah Arbabisarjou ${ }^{1}$ \\ ${ }^{1}$ Health Promotion Research Center, Zahedan University of Medical Sciences, Zahedan, IR Iran \\ ${ }^{*}$ Corresponding author: Hossein Ansari, Health Promotion Research Center, Zahedan University of Medical Sciences, Zahedan, IR Iran. Tel: +98-9126309480, Fax: +98-5433425375, \\ E-mail:ansarih88@gmail.com
}

Received 2015 October 5; Revised 2015 November 7; Accepted 2015 November 9.

\begin{abstract}
Background: Several factors are responsible for overuse of the internet among young adults. The practice can lead to internet addiction (IA). In addition, users' happiness may be an important factor related to IA, and should be assessed.

Objectives:The present study aims to estimate the prevalence of internet addiction (IA) and its relationship to happiness among students enrolled at the Zahedan University of Medical Sciences (ZUMS) in southeastern Iran.

Patients and Methods: This cross-sectional study was carried out on 380 medical students at ZUMS in 2015. The subjects were selected using the stratified random sampling method. The data were collected using Yang Standard Internet Addiction and Oxford Happiness questionnaires, and were analyzed in Stata.12 software using bivariate and multiple logistic regression with the Hosmer-Lemshow method. Results: The prevalences of IA among males and females were 33.8\% (95\% CI: 26.1 - 41.5) and 20\% (95\% CI:14.9 - 25.1), respectively. The results of logistic regression analyses revealed that gender $(\mathrm{OR}=1.98,95 \% \mathrm{CI}: 1.48-2.48)$, average grades $(\mathrm{OR}=0.87,95 \% \mathrm{CI}$ : 0.81 - 0.99$)$, and happiness scores (OR $=0.82,95 \%$ CI: $0.75-0.98)$ were statistically significantly associated with IA. However, IA was not associated with subjects' age, semester of study, residential area, or school of education $(\mathrm{P}>0.05)$.

Conclusions: The prevalence of IA among medical students in southeast Iran was high and affected by happiness. Increasing happiness with the provision of various programs may prevent IA problems among students and may improve their educational situation.
\end{abstract}

Keywords: Internet Addiction, Students, Medical, Happiness

\section{Background}

The internet is one of the most important devices in the global system, and it is increasingly used by people around the world who are looking for access to information. In the meantime, medical students use the internet as a source for health-related information (1-4). The internet is a cost-effective, quick, and useful education tool (5), so much so that students use it for both academic and recreational purposes (4). However, sometimes people, especially adolescents and young adults such as students, use the internet too much for entertainment and leisure time. This may lead to the wasting of students' useful time (6). For this reason, internet addiction (IA) can be regarded as one of the complications brought on by widespread internet access.

Internet use is common and inevitable around the world, but frequent and prolonged periods of use are associated with psychological and sociological problems $(3,7)$. Sleep problems, musculoskeletal disorders, back pain, and nutritional problems such as overweight status are some of complications associated with $\operatorname{IA}(7,8)$.
The prevalence of IA among adolescents has been reported various from regions around the world. The prevalence of IA among adolescents is reported at 22.5\% in Hong Kong (9), 8.8\% in China (10), 3.1\% in Greece (11) and about $15.1 \%$ in Turkey (12). In Iran, a study of middle and high school adolescents revealed that 21.1\% have IA; among them, that $1.1 \%$ had significant problematic symptoms (13). Another study in Iran reported that $3.7 \%$ of a sample of Iranian internet-using adolescents were internet addicts (14).

It is worth mentioning that happiness, as a basic human emotion, has an important role in individual and societal health. On the other hand, increasing happiness may be an effective means of increasing the performance of people in different occupations; further study of its effects is recommended. Happiness is one of the essential components of quality of life (15). In addition, happiness is a factor likely to be found to be associated with IA disorder $(16,17)$, as people with low levels of happiness have a greater tendency toward heavier internet use. However, further stud-

Copyright (C) 2016, Health Promotion Research Center. This is an open-access article distributed under the terms of the Creative Commons Attribution-NonCommercial 4.0 International License (http://creativecommons.org/licenses/by-nc/4.0/) which permits copy and redistribute the material just in noncommercial usages, provided the original work is properly cited. 
ies are needed to prove this relationship. It should also be mentioned that those with IA have many other psychiatric symptoms, such as depression and low levels of happiness, so it could be suggested that overuse of the internet could be due to low happiness and/or decreasing levels of happiness (18-20). Ultimately, there is a reciprocal relationship between measures of IA and happiness. Therefore, studies in this area, especially among university students, are too important to ignore, and the results could help authorities and psychologists to plan preventive programs regarding these disorders in young people.

To date, no comprehensive study has addressed the relationship between IA and happiness among university students. On the other hand, the internet is growing in popularity, especially among adolescents and students in Iran (21), and parents have concerns about their children's excessive use and its consequences. Thus, the results of our study can provide useful insights to the predictors of IA, which can be used by relevant authorities to identify high-risk groups and to devise plans for effective educational programs aimed at the prevention of IA.

\section{Objectives}

This study was conducted to estimate the prevalence of IA and some of the factors related to it, such as happiness, among students at ZUMS, in southeastern Iran. The study aim to encourage and inform interventions and future research agendas regarding medical students. Due to a lack of data on Sistan and Baluchestan province, the results of this study (so far as we know, this is the first study in this region) can also provide a basis for comparison in future epidemiological studies.

\section{Patients and Methods}

This cross-sectional study was carried out on 380 medical students at ZUMS, in southeast Iran, in 2015. The subjects were selected using a two-stage random sampling method. As there were six schools in our study, with unequal populations and different levels of education, students were first selected via a stratified proportional sampling method based on level and school. In the next step, for each stratum, students were selected by a simple random sampling method based on the sample frame (the list of the students' names in each stratum, as prepared by the educational office of each school). It must be mentioned that the sample size of each stratum was proportionally based on its total student population. The statistical population consisted of all of the students at ZUMS, including 2351 females and 1376 males. Students in their first term of study were excluded from the study. The ZUMS Ethics Committee approved of the study, and informed consent was received from the students before collecting the data. To enhance the validity of the students' self-reports, they were assured of the strict confidentiality of their responses and that they could not be recognized by their answers. They were also informed about the voluntary nature of their participation in the study and their right to refuse or skip any questions.

The data were collected using a structured questionnaire. The first section of the questionnaire contained demographic variables such as age, gender, average annual score, and so on. The second section was the reliable and standard Yang Questionnaire for Measuring Internet Addiction. The questions for IA were scored using a 5-point Likert scale, ranging from 1 to 5 , so this test produced a potential range of 20 to 100, with higher scores indicating a greater tendency toward addiction. In this study, according to other recent studies (6), a score of 50 or above was considered indicative of IA. The Persian language reliability and validity of this questionnaire was approved in previous studies in Iran (22-25); The validity of the questionnaire was approved with at least 0.83 content validity index (CVI) for every question by ten experts, and the reliability was approved by $\mathrm{r}=0.81 \mathrm{using}$ test-retest correlation (Pearson correlation coefficient) in 30 medical students with a two-week interval. The third section of the structured questionnaire was the reliable and standard Oxford Happiness Questionnaire, designed to measure happiness. Twenty-nine questions for happiness in this questionnaire are scored using a 4-point scale, ranging from 0 to 3, so this test produced a potential range of 0 to 87 , with higher scores indicating a greater level of happiness. Alipoor (26) approved the reliability and validity of this questionnaire in the Persian language. Eight experts approved the questionnaire's validity with at least 0.88 CVI for every question. The reliability was approved by Cronbach's alpha $=0.92$ and $r=0.78$ using a test-retest correlation (Pearson correlation coefficient) in 33 medical students with a two-week interval. The normality of happiness score was approved by the Shapiro-Wilk test.

Chi-square and independent sample t-tests were used to examine the unadjusted association between related risk factors and IA in the bivariate analysis. Moreover, a multiple logistic regression was used to investigate the effect of predicting factors on IA among medical students by controlling potential confounders. The Hosmer and Lemeshow test was used to model estimations and to evaluate the goodness-of-fit of the logistic regression model (27). This method involves the following steps: 1-A bivariate analysis of each independent variable is used by logistic regression. Any variable whose bivariate test has a p-value of less than 0.2 should be included in the first multiple model. 2- A multiple model containing all covariates identified for inclusion at Step 1, and to assess the importance of each covariate using the p-value of its Wald statistic. Variables that do not contribute at traditional levels of significance should be eliminated and a new model fit. The newer, smaller model should be compared to the old, larger model using the partial likelihood ratio test (LR test).3-Compare the values of the estimated coefficients in the smaller model to their respective values from the large 
Ansari $\mathrm{H}$ et al.

model. Any variable whose coefficient has changed markedly in magnitude should be added back into the model, as it is important in the sense of providing a needed adjustment of the effect of the variables that remain in the model. Cycle through Steps 2 and 3 until it appears that all of the important variables are included in the model and those excluded are clinically and/or statistically unimportant. 4-Add each variable not selected in Step 1 to the model obtained at the end of Step 3, one at a time, and check its significance either by the Wald statistic p-value or the partial LR test, if it is a categorical variable with more than two levels. The data were analyzed using Stata.12 software. The significance level was defined as $\mathrm{P}<0.05$.

\section{Results}

\subsection{Sample Characteristics}

A total of 380 students participated in our study. The average age of the students in the sample was $21.4 \pm 2.6$ (min. 18 and max. 27). Of all the subjects, 235 (61.8\%) were females and 145 (38.2\%) were males. The mean average grade of the students was $15.9 \pm 1.4$ (Median: 16.1). In this study, $77.3 \%(n=294)$ of the students lived in a dormitory. About $32.4 \%, 10.5 \%, 17.1 \%, 14.7 \%, 8.9 \%$, and $16.3 \%$ of the students were from the medical, dental, paramedical, health, rehabilitation, and nursing faculties, respectively. Further, 3.4\%, 19.4\%, 9.2\%, 19.2\%, 11.8\%, 16.1\%, and 9.9\% of the students were in their second to eighth semester, respectively, and the others were in higher terms.

\subsection{Prevalence of IA}

Table 1 shows the prevalence of IA by gender. As reported in the table, $18.4 \%$ and $6.9 \%$ of the students had IA scores $50-79$ and $80-100$, respectively. The prevalence of IA was higher among males compared to females. After considering IA as a score of 50 or greater, the prevalence of IA was 33.8\% (95\% CI: 26.1 - 41.5) in males and 20\% (95\% CI: 14.9 - 25.1) in females. The overall prevalence of IA for the entire sample was $25.3 \%$ (95\% CI: 20.9 - 29.6). The chi-square test showed that the prevalence between the genders is significantly different $(\mathrm{P}=0.001)$ (Table 1$)$. Also, the mean of the Yang questionnaire scores was $41.4 \pm 13.8$. The mean IA scores among male and female students were $46.5 \pm$ 16.9 and $43.9 \pm 9.5$, respectively $(\mathrm{P}=0.009)$. On the other hand, the mean Oxford happiness score was $39.6 \pm 13.5$. The mean of happiness scores among male and female students was $38.25 \pm 10.5$ and $40.44 \pm 9.4$, respectively (P $=0.04)$.

\subsection{IA and Socio-educational Variables}

The results of bivariate analyses indicated that IA was statically significantly associated with the male gender, higher semesters and lower average grades (Table 2). The prevalence of IA was higher among males and lower grade students compared to females and higher grade students. Students with low average grades and higher semesters were more likely to be IA.

\subsection{IA and Happiness}

Internet addiction was found to be associated with happiness. The mean happiness scores in students with and without IA were $36.1 \pm 10.21$ and $44.34 \pm 13.33$, respectively $(\mathrm{P}=0.001)$. On the other hand there was a negative correlation between IA scores and happiness scores $(r=-0.47$, $\mathrm{P}=0.004)$.

\subsection{Predictors of IA}

The results of logistic regression analyses with the Hosmer-Lemeshow method indicated that gender (OR $=1.98,95 \% \mathrm{CI}: 1.48-2.48)$, average grade $(\mathrm{OR}=0.87,95 \% \mathrm{CI}$ : $0.81-0.99)$, and happiness scores (OR $=0.82,95 \% \mathrm{CI}: 0.75$ - 0.98) were statistically significantly associated with IA and remained in the final model. As an interpretation of the calculated ORs, it should be noted that the chance of internet overuse among males is more common than among females. Also, the likelihood of IA among students with low average grades and happiness scores is greater than among others. Although the variable "school of education" was not statistically significantly associated with IA, it improved the likelihood of the final model (Table 3).

Table 1. Prevalence of Internet Addiction and Happiness Scores, by Gender, Among Students at ZUMS in Southeastern Iran ${ }^{\mathrm{a}}$

\begin{tabular}{lccc}
\hline IA Scores & Males & Females & Total \\
\hline $\mathbf{2 0}-\mathbf{4 9}$ & $96(66.2)$ & $188(80)$ & $284(74.7)$ \\
$\mathbf{5 0}-\mathbf{7 9}$ & $35(24.1)$ & $35(14.9)$ & $70(18.4)$ \\
$\mathbf{8 0}-\mathbf{1 0 0}$ & $14(9.7)$ & $12(5.1)$ & $26(6.9)$ \\
\hline Total & $145(100)$ & $235(100)$ & $380(100)$ \\
\hline Happiness score, mean \pm SD & & $40.44 \pm 9.4$ & $39.6 \pm 13.5$ \\
\hline
\end{tabular}

a Data are presented as No.(\%). 
Ansari H et al.

Table 2. The Results of the Bivariate Analyses of the Relationship Between Socio-educational Variables and Internet Addiction (IA) Among Students at ZUMS in Southeastern Iran

\begin{tabular}{|c|c|c|c|}
\hline Variables & IA Present & IA Not Present & P Value \\
\hline Total observation: 380 & $96(25.3)$ & $284(74.7)$ & \\
\hline Gender & & & .002 \\
\hline Male & $49(33.8)$ & $96(66.2)$ & \\
\hline Female & $47(20)$ & $188(80)$ & \\
\hline Residential area & & & .054 \\
\hline Dormitory & $68(23.1)$ & $226(76.9)$ & \\
\hline Private Home & $28(32.6)$ & $58(67.4)$ & \\
\hline Semester & & & .001 \\
\hline Second & $2(15.4)$ & $11(84.6)$ & \\
\hline Third & $15(20.3)$ & $59(79.7)$ & \\
\hline Fourth & $14(40)$ & $21(60)$ & \\
\hline Fifth & $31(42.5)$ & $42(57.5)$ & \\
\hline Sixth or higher & $34(18.4)$ & $151(81.6)$ & \\
\hline School of education & & & .17 \\
\hline Medical & $33(26.8)$ & $90(73.2)$ & \\
\hline Dental & $16(40)$ & $24(60)$ & \\
\hline Health & $13(23.2)$ & $43(76.8)$ & \\
\hline Nursing & $16(25.8)$ & $46(74.2)$ & \\
\hline Paramedical & $11(16.9)$ & $54(83.1)$ & \\
\hline Rehabilitation & $7(20.6)$ & $27(79.4)$ & \\
\hline Age & $21.64 \pm 1.95$ & $21.25 \pm 2.76$ & .5 \\
\hline Average grades & $15.69 \pm 1.36$ & $16.1 \pm 1.48$ & .023 \\
\hline Variables & OR & $\mathbf{9 5} \% \mathrm{CI}$ & PValue \\
\hline Gender (Male/Female) & 1.98 & $1.48-2.48$ & 0.001 \\
\hline \multicolumn{4}{|l|}{ School of education } \\
\hline Health & 1 & NA & NA \\
\hline Medical & 1.24 & $0.85-1.31$ & 0.41 \\
\hline Dental & 1.15 & $0.61-1.13$ & 0.34 \\
\hline Nursing & 1.02 & $0.43-1.21$ & 0.51 \\
\hline Paramedical & 0.83 & $0.73-2.18$ & 0.21 \\
\hline Rehabilitation & 0.98 & $0.81-1.93$ & 0.41 \\
\hline Higher happiness score & 0.82 & $0.75-0.98$ & 0.031 \\
\hline Average grades (higher score) & 0.87 & $0.81-0.99$ & 0.049 \\
\hline
\end{tabular}

Abbreviation: NA; not available.

\section{Discussion}

This study showed that the overall prevalence of IA among students at ZUMS is $25.3 \%$. According the findings of this study, the prevalence of IA among students at ZUMS, in southeastern Iran, is much greater than the reported prevalence noted in previous studies conducted in Iran and around the world (9-11, 14, 21, 28, 29). Although previous work in Iran showed that the IA phenomenon has been increasing among adolescents $(21,28)$, the study population, place, and time of study could explain these results. On the other hand, there is an increasing trend toward IA over time and with the use of the internet; this is predictable, as internet facilities and use have increased in Iran in recent years. However, it seems that more IA and students' tendencies to use desktop computers, tablets, laptops, and cell phones could be due to increasing connectivity. This effect could be linked to the use of mobile devices in Iranian universities in recent years. More emotional behavior and curiosity among university stu- 
Ansari $H$ et al.

dents, compared to the general population, could be another explanation for these results.

The moderate and severe levels of IA indicated by the present study, estimated at $18.4 \%$ and $6.9 \%$, respectively, are greater than those found in previous studies in Iran (6) and Australia (30). These results show the increasing overuse of the internet among Iranian adolescents and students.

In this study, the prevalence of IA was more common among males than females. This result is similar to some previous studies conducted in university settings in Iran and other studies around the world $(6,21,31,32)$. More specifically, communicating with the opposite sex in Iranian universities is common, and students use the internet to communicate with one other in some cases; usually the males initiate these interactions. Therefore, the gender difference of IA in Iran's universities is anticipated. Males and females have different preferences for their internet activities, and these may depend on the type of activities in which they engage (33) and the users' expectations of them, this explaining gender differences in internet use (15). The reported gender difference in the distribution of IA can also be explained by the fact that males, compared to females, generally have more social freedom, friends, and membership in social networks in Iran. However, the problem is that the students may spend their time in chat rooms or use the internet for computers games. In this case, use of internet will lead to more complications and increase the likelihood of IA. Thus it is recommended that the students receive necessary education related to this field at the beginning of their university studies.

In the present study, the mean age of the students with IA was greater than that of students without IA, but this difference was not statistically significant. This result is not concordant with previous studies in Iran and around the world $(6,32,34)$. On the other hand, in a bivariate analysis, the students with higher semesters had a greater tendency toward IA. It seems that students are influenced by each other and become more familiar with computer games in the university during higher semesters. Further, the students in lower semesters in Iran, especially at ZUMS, are less familiar with the internet. The previous study in Iran (35) showed that using the internet is associated with the skill of using the internet; however, offering free internet in Iran's universities could be another reason for IA among students.

Based on the results of our study, the prevalence of IA among students in low average grades was more than among those in high average grades. This finding was contrary to the results of a national level study conducted in Iran (36). Most of the students with IA use the internet illogically, for gaming and spending time on entertainment sites. These students have different personalities and seemed bored with the study. Therefore, it could be concluded that IA leads to lower average grades among students. It is recommended that the students with low average grades be screened for IA every semester by the educational affairs authorities at their universities.
We found a negative association between happiness and IA in this study. This result is in line with previous studies around the world $(16,17)$. In fact, adolescents with communication and social problems are more unsociable (37) and less fewer collective and happy programs; thus, they like privacy and prefer to spend many hours on the Internet. On the other hand, IA might be due to behavioral disorders in adolescents, which decrease their happiness. Further, individuals with low happiness levels and poor communication skills are more anxious and consequently have more IA (36-37). Some studies have already noted that there is a positive correlation between mental health and negligence. There is also a positive association between mental health and the excessive use of the Internet. Depressed and low self-esteem students have low levels of happiness, which, in turn, increase their tendency to be IA and lead to them seeking time alone $(37,38)$. It seems that introverted individuals often have lower happiness levels and do not communicate with extroverted individuals. People lacking self-esteem are often introverted as well, and have lower levels of happiness; they are more susceptible to become addicted to the internet, just as they are more likely to use alcohol and drugs (39). Previous studies have shown that there is a relationship between loneliness, a lack of confidence, a lack of social skills, and internet use, and addicted students are more interested in using the internet as a means of ensuring their privacy $(14,37)$. Thus, it seems that people with low levels of happiness are lonely, and vise versa. Still, further investigation in this field is needed, though university authorities should determine which students who have more problems and then screen the low happiness ones. Finally, universities should periodically provide various and happy programs for students.

There are several limitations to our study. First, although the cross-sectional nature of the study provided evidence of an association between predictor variables and IA, it could not establish temporality between predictor variables and IA, precluding causal inference. Second, in spite of the satisfactory methodology and sampling design method, our findings should not be generalized to all universities in Iran, because our sample derived from a medical sciences university in southeast Iran whose atmosphere is different from that of other Iranian universities.

\subsection{Conclusion}

The overall prevalence of internet addiction among Zahedan medical students is markedly different from other regions. Unfortunately, most of the time, students are unaware of the complications of IA, therefore, university authorities should try to educate and explain to students how to use the internet logically. Also, students should be encouraged to use the internet to review academic papers and access other beneficial sites. Improvements in family relations, such as family functioning and improved cohesion, especially among unsociable and low happiness 
score students, may mitigate the IA problem among university students. It seems that collaboration between parents, teachers, and university authorities in warning and changing students' attitudes towards their lives, especially in the beginning semesters of university, could more effectively address the emerging phenomenon of IA.

\section{Acknowledgments}

The authors appreciate the students who participated in this study.

\section{Footnotes}

Authors' Contribution:Project managers and designers of the research: Hossein Ansari and Alireza Ansari Moghaddam; collaborated in analyzing data and writing the paper: Azizollah Arbabisarjou, Mahdi Mohammadi; collaborated in collecting data and prepared the literature review: Mostafa Peyvand and Zahra Amani.

Funding/Support:This study was supported financially by the Student Research Committee of the Zahedan University of Medical Sciences.

\section{References}

1. Aboujaoude E. Problematic Internet use: an overview. World Psychiatry. 2010;9(2):85-90. [PubMed: 20671890]

2. Ayatollahi J, Ayatollahi F, Bahrololoomi R. Using the internet among dental students in Yazd. Dent Res J(Isfahan). 2010;7(1):7-11. [PubMed: 21448440]

3. Ko CH, Yen JY, Chen CS, Chen CC, Yen CF. Psychiatric comorbidity of internet addiction in college students: an interview study. CNS Spectr. 2008;13(2):147-53. [PubMed: 18227746]

4. Swaminath G. Internet addiction disorder: Fact or Fad? Nosing into Nosology. Indian J Psychiatry. 2008;50(3):158-60. doi: 10.4103/0019-5545.43622. [PubMed: 19742232]

5. Castren J, Huttunen T, Kunttu K. Users and non-users of webbased health advice service among Finnish university students - chronic conditions and self-reported health status (a cross-sectional study). BMC Med Inform Decis Mak. 2008;8:8. doi: 10.1186/1472-6947-8-8. [PubMed: 18237414]

6. Ghamari F, Mohammadbeigi A, Mohammadsalehi N, Hashiani AA. Internet addiction and modeling its risk factors in medical students, iran. Indian J Psychol Med. 2011;33(2):158-62. doi: 10.4103/0253-7176.92068. [PubMed: 22345841]

7. Kim YS, Ahn DH, Kim YY. The relationship between problematic internet use and health risk behavior in community high school students. J Korean Acad Child Adolescent Psyche. 2007;18(2):130-7.

8. Suris IC, Akre C, Piguet C, Ambresin AE, Zimmermann G, Berchtold A. Is Internet use unhealthy? A cross-sectional study of adolescent Internet overuse. Swiss Med Wkly. 2014;144:w14061. doi: 10.4414/smw.2014.14061. [PubMed: 25474244]

9. Yu L, Shek DT. Internet addiction in Hong Kong adolescents: a three-year longitudinal study. J Pediatr Adolesc Gynecol. 2013;26(3 Suppl):S10-7. doi: 10.1016/j.jpag.2013.03.010. [PubMed: 23683821]

10. Xu J, Shen LX, Yan CH, Hu H, Yang F, Wang L, et al. Personal characteristics related to the risk of adolescent internet addiction: a survey in Shanghai, China. BMC Public Health. 2012;12:1106. doi 10.1186/1471-2458-12-1106. [PubMed:23259906]

11. Stavropoulos V, Alexandraki K, Motti-Stefanidi F. Recognizing internet addiction: prevalence and relationship to academic achievement in adolescents enrolled in urban and rural Greek high schools. J Adolesc. 2013;36(3):565-76. doi: 10.1016/j.adolescence.2013.03.008. [PubMed:23608781]

12. Sasmaz T, Oner S, Kurt AO, Yapici G, Yazici AE, Bugdayci R, et al Prevalence and risk factors of Internet addiction in high schoo students. Eur J Public Health. 2014;24(1):15-20. doi: 10.1093/eurpub/ckt051. [PubMed: 23722862]

13. Ahmadi K, Saghafi A. Psychosocial profile of Iranian adolescents' Internet addiction. Cyberpsychol Behav Soc Netw. 2013;16(7):543-8. doi:10.1089/cyber.2012.0237. [PubMed: 23614793]

14. Ghassemzadeh L, Shahraray M, Moradi A. Prevalence of internet addiction and comparison of internet addicts and non-addicts in Iranian high schools. Cyberpsychol Behav. 2008;11(6):731-3. doi 10.1089/cpb.2007.0243. [PubMed:18954277]

15. Rajabi-Gilan NGS, Reshadat S, Zangeneh A. Happiness in Health Sector Personnel; Some Demographic and Occupational Related Factors. J Isfahan Med Sch. 2015;32(309):1897-906.

16. Akin A. The relationships between Internet addiction, subjective vitality, and subjective happiness. Cyberpsychol Behav Soc Netw. 2012;15(8):404-10. doi: 10.1089/cyber.2011.0609. [PubMed 22823517]

17. Uysal R, Satici SA, Akin A. Mediating effect of Facebook addiction on the relationship between subjective vitality and subjective happiness. Psychol Rep. 2013;113(3):948-53. doi: 10.2466/02.09.18. PR0.113x32z3. [PubMed: 24693824]

18. Armstrong L, Phillips J, Saling L. Potential determinants of heavier internet usage. Wiadomosci Psychiatryczne . 2012;15(3):118-27.

19. Shaw LH, Gant LM. In defense of the Internet: The relationship between Internet communication and depression, loneliness, self-esteem, and perceived social support. Cyber Psychol Behav. 2002;5(2):157-71. doi: 10.1089/109493102753770552.

20. Young KS, Rogers RC. The relationship between depression and Internet addiction. Cyber Psychol Behav. 1998;1(1):25-8. doi: 10.1089/cpb.1998.1.25.

21. Nasiri E, Raei M, Vatani J, Keshavarz S, Almasi Hashiani A. Survey the Prevalence of Internet Addiction and its Influential Factors in Persian College Student in 2011. Middle East J Sci Res 2011;10(1):50-3.

22. Alavi SS, Jannatifard F, Eslami M, Rezapour H. Survey on validity and reliability of diagnostic questionnaire of internet addiction disorder in students users. Zahedan J Res Med Sci. 2011;13(7):34-8.

23. Mohamadbeigi A, Ghazavi A, Ghamari F, Saeidi A. Effect of internet addiction on educational status of Arak University of medical sciences students, spring 2009. Arak Med U J. 2010;12(4):95-102.

24. Mohammadbeigi A, Mohammadsalehi N. Prevalence of Internet Addiction and Related Risk Factors in Students. J Guilan U Med Sci. 2011;20(2):41-8.

25. Mohammadsalehi N, Mohammadbeigi A, Jadidi R, Anbari Z Ghaderi E, Akbari M. Psychometric Properties of the Persian Language Version of Yang Internet Addiction Questionnaire: An Explanatory Factor Analysis. Int J High Risk Behav Addict. 2015;4(3):e21560. doi: 10.5812/ijhrba.21560. [PubMed: 26495253]

26. Alipoor A, Noorbala A. A preliminary evaluation of the validity and reliability of the Oxford happiness questionnaire in students in the universities of Tehran. Iranian J Psyche Clin Psychol (Andeesheh Va Raftar). 1999;5(17-18):55-65.

27. Hosmer J, David W, Lemeshow S. Applied logistic regression.3rd ed USA: John Wiley \& Sons; 2004.

28. Kheirkhah F, Gouran A. Internet Addiction, Prevalence and Epidemiological Fea-tures in Mazandaran Province, Northern Iran. Iranian Red Crescent Med J . 2010;2010(2):133-7.

29. Yadav P, Banwari G, Parmar C, Maniar R. Internet addiction and its correlates among high school students: a preliminary study from Ahmedabad, India. Asian J Psychiatr. 2013;6(6):500-5. doi: 10.1016/j.ajp.2013.06.004. [PubMed: 24309861]

30. Lam LT, Peng ZW, Mai JC, Jing J. Factors associated with Internet addiction among adolescents. Cyberpsychol Behav.2009;12(5):5515. doi: 10.1089/cpb.2009.0036. [PubMed:19619039]

31. Ceyhan AA. Predictors of problematic Internet use on Turkish university students. Cyberpsychol Behav. 2008;11(3):363-6. doi: 10.1089/cpb.2007.0112. [PubMed:18537510]

32. Tsai HF, Cheng SH, Yeh TL, Shih CC, Chen KC, Yang YC, et al. The risk factors of Internet addiction--a survey of university freshmen. Psychiatry Res. 2009;167(3):294-9. doi: 10.1016/j.psychres.2008.01.015. [PubMed:19395052]

33. Hawi NS. Internet addiction among adolescents in Lebanon. Computers Human Behav. 2012;28(3):1044-53. 


\section{Ansari H et al.}

34. Bastani S. Gender Division in Computer and Internet Application: Investigation of the Students of Tehran Universities. Women Studies. 2008;5(1):45-64.

35. Dargahi H, Razavi SM. Internet addiction and its related factors: A study of an Iranian population. J Payesh. 2007;6(2):265-72.

36. Ahmadi K. Internet addiction among Iranian adolescents: a nationwide study. Acta Med Iran. 2014;52(6):467-72. [PubMed:25130156]

37. Mostafaei A, Khalili M. The relationship between Internet addic- tion and mental health in male and female university students. Annals Biol Res. 2012;3(9):4362-6.

38. Jalalinejad R, Ghasempoor A, Ajdari Z, Sadeghigooghari N. The relationship between Internet addiction and anxiety in the universities' students. Interdiscipl J Contemp Res Bus. 2012;4(1):942-9.

39. Chak K, Leung L. Shyness and locus of control as predictors of internet addiction and internet use. Cyberpsychol Behav. 2004;7(5):559-70. [PubMed:15667051] 